\title{
Hazards associated with municipal waste storage Vol. II
}

\author{
Anna Dmochowska ${ }^{1, *}$ \\ ${ }^{1}$ The Main School of Fire Service, Faculty of Fire Safety Engineering, 52/54 Slowackiego St., \\ 01-629 Warsaw, Poland
}

\begin{abstract}
Municipal waste storage leads to many threats to all elements of the environment. Among other things, are suspended dusts. Before closing the plot designated for storing a given portion of waste, the unprotected volatile parts contained in it are emitted, including dusts. They can be a serious pathogenic agent, transferring microtoxins, heavy metals and other pollutants. Depending on the size, they settle on the walls of the alveoli, making gas exchange difficult, causing irritation to the epidermis and mucous membranes, inflammation of the upper respiratory tracts and cause allergic diseases such as asthma. They can also cause lung, throat and larynx cancer. The aim of the research was to measure the concentration of suspended dust in the areas adjacent to the landfill. The DustTrak II dust meter was used for the tests. Dust concentrations measurements were made for orientation purposes (to plan measurements in subsequent years). The obtained results indicate that the permissible dust concentrations are exceeded even though the landfill is already closed, and the landfill top and side escarpments were being reclamation.
\end{abstract}

\section{Introduction}

The time the dust remains in the atmosphere and its spread depends on the height on which it floats, climatic conditions and the size of their particles. $\mathrm{PM}_{10}$ dust is transported up to $1000 \mathrm{~km}$ and can be removed from the atmosphere, among others through sedimentation or a few hours of rainfall. In turn, $\mathrm{PM}_{2.5}$ dusts can be transported over a distance of up to 2500 $\mathrm{km}$ [1-4]. They settle on the walls of the alveoli, obstructing gas exchange, causing irritation of the epidermis and mucosa, inflammation of the upper respiratory tract [5-7]. They cause allergic diseases, asthma, lung, throat and larynx tumors [8-11]. There is no concentration threshold below which the negative health effects resulting from dust exposure to human health do not occur [12-15]. People who have been diagnosed with respiratory and cardiovascular diseases, children and seniors are particularly vulnerable to their effects [16-19]. Often their action is activated by the presence of other substances, e.g. heavy metal compounds deposited on them [20-26]. Depending on the solubility of dust in body fluids and their crystal structure, they may have irritating, fibrosing, carcinogenic and allergenic effects [27-29]. The inhalable dusts with aerodynamic diameters smaller than 10 $\mu \mathrm{m}$ can be deposited in the upper respiratory tract and lungs [30-34]. These particles are

\footnotetext{
*Corresponding author: admochowska@sgsp.edu.pl
} 
designated as $\mathrm{PM}_{10}$ [35-37]. Respirable dust with grain diameters smaller than 2.5 and 1.0 $\mu \mathrm{m}$ are denoted as $\mathrm{PM}_{2.5}$ and $\mathrm{PM}_{1.0}$, respectively [38-40]. These dusts can penetrate directly into the lungs and also enter the bloodstream [41-43]. Dust suspended also has a negative effect on plant organisms [44]. It hinders the process of photosynthesis because it settles on the surface of leaves, absorbs light, clogs stomata [45]. Pollution of the atmospheric air with dust is closely related to the intensive development of the human economic activity [46]. Among many kinds of this activity, transport takes a significant place [47]. However, the presence of a municipal waste landfill for nearby towns during its operation, when the quarters are not yet secured, also has a very large impact on the spread of particulate matter [48]. With the closure of the landfill, the risk associated with the emission of dust does not disappear [49]. Dusts emitted from the landfill during its operation were deposited in the areas around it [50]. From this area, depending on the conditions, they can be released [51]. Therefore, land at the landfill, even after its reclamation, should be monitored for concentrations of suspended dust [52].

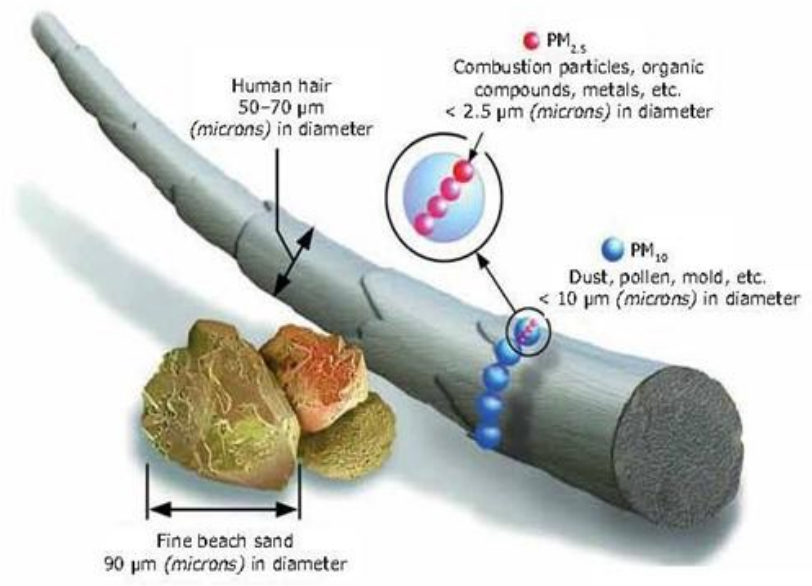

Fig.1. Dust sizes compared to the size of a human hair [53].

\section{Material and methods}

The aim of the study was to make an approximate estimate of suspended particulate concentrations in areas adjacent to the landfill in 2014-2015. As part of the preliminary tests, two measurement series were set up, located at the height of the manholes with taken up leachates (vol I).

The Figure 2 shows the direction of the route of the measurement points of suspended dust. 


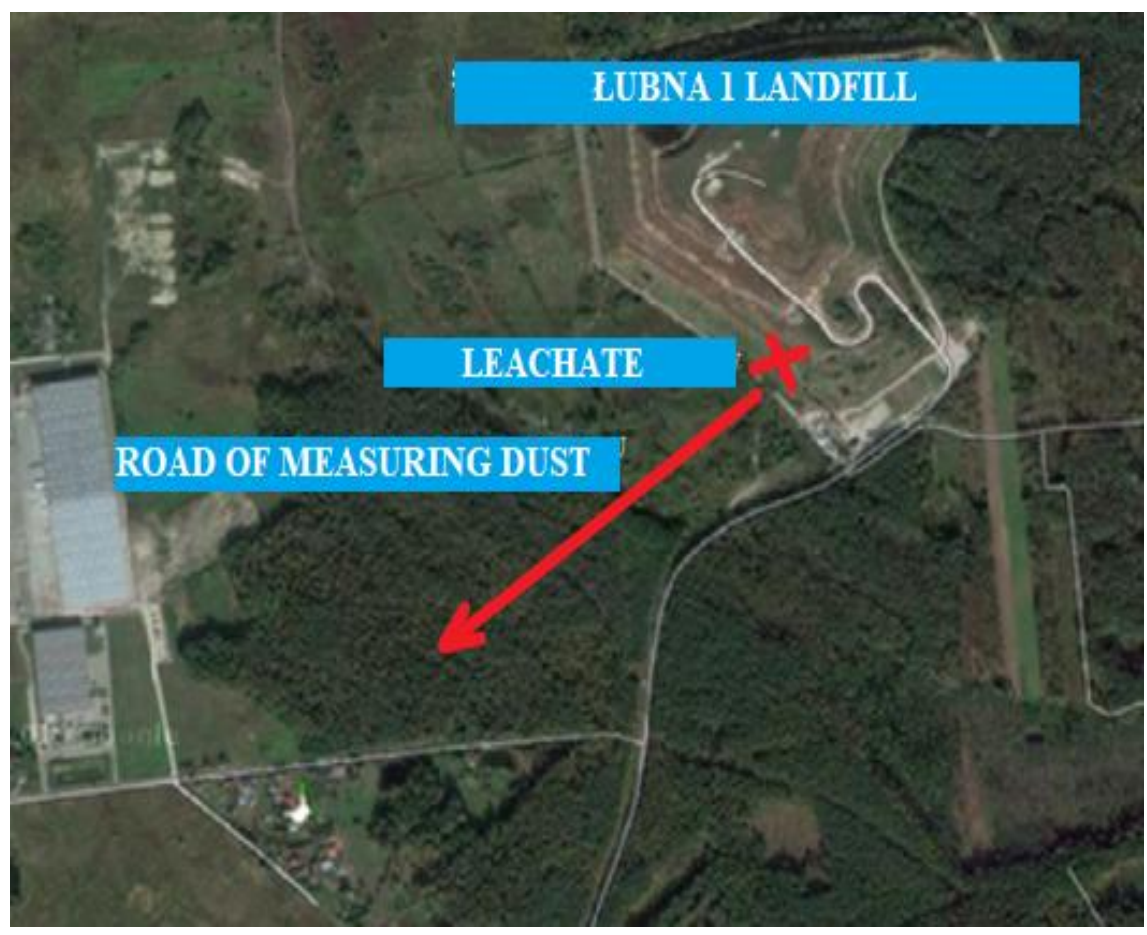

Fig. 2. Direction of route of measurement points of suspended dust.

For indicative, preliminary tests of suspended particulate concentrations, 8 points (two parallel routes) were selected, in which the suspended dust was measured for the fraction analysis: $\mathrm{PM}_{10}, \mathrm{PM}_{2.5}$. They were located at a distance of 20, 40, 100, 150, 200, 300, 500, $600 \mathrm{~m}$ from the well 1 from which the effluents were collected and at the same distances from well 2, distant from well no. 1 by approx. $50 \mathrm{~m}$ and from access road about $100 \mathrm{~m}$. Each measurement was made at a height of $1.5 \mathrm{~m}$ from the earth's surface. Air samples were collected three times a year and then the result was averaged. The DustTrack II dust meter was used to test the content of dust suspended in the air, distinguishing the fraction.

\section{Results}

Figures 3-7 presents the distribution of dust suspended at designated points, located in the following distances from both selected wells with leachate. 


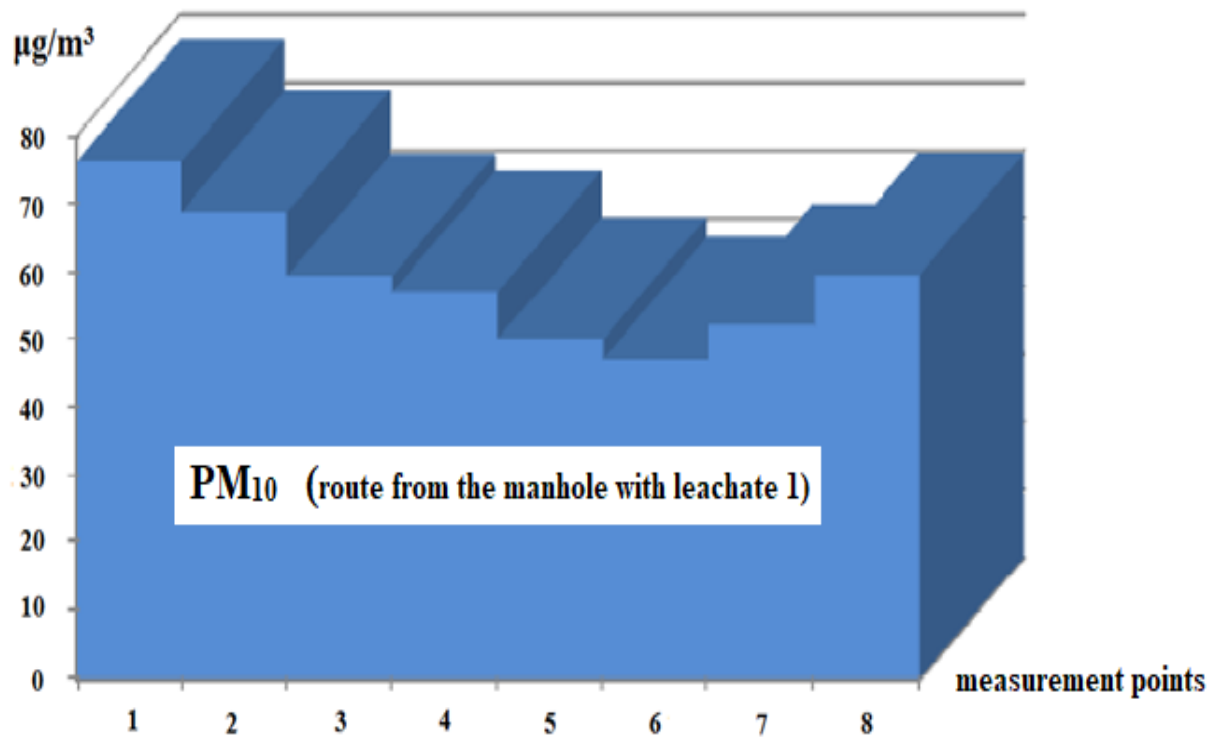

Fig. 3. Distribution of $\mathrm{PM}_{10}$ dust concentrations in the following distances from the manhole with the leachate 1 .

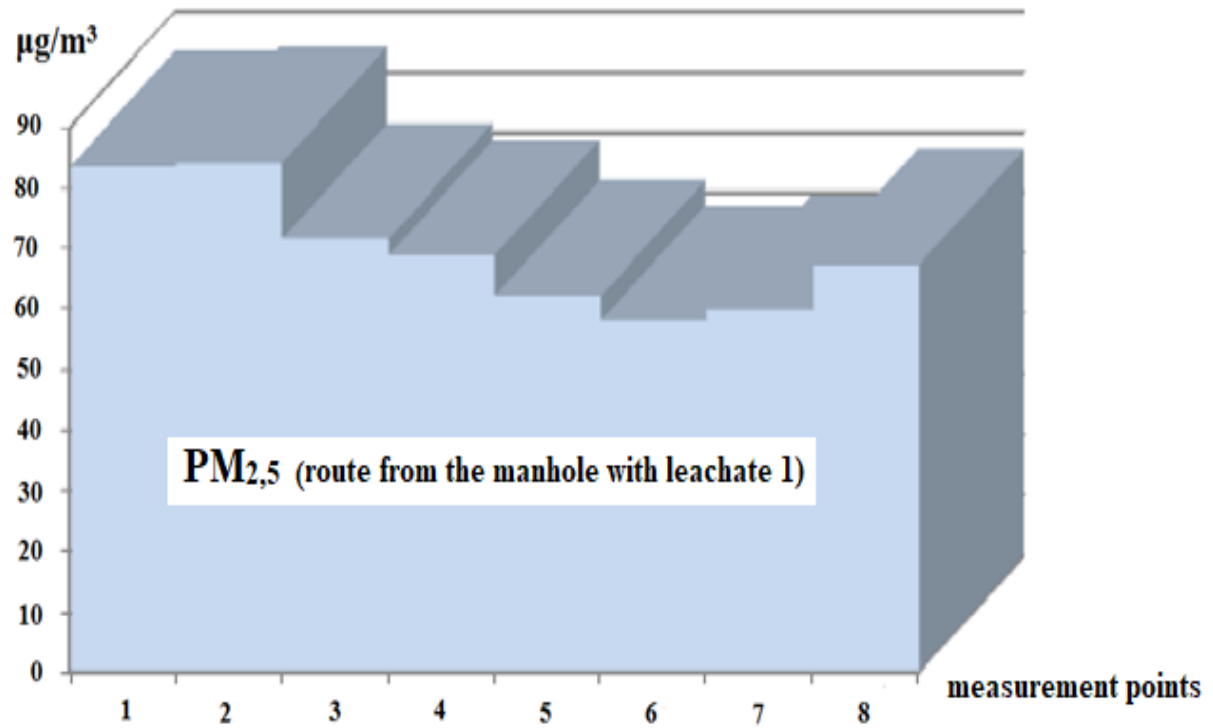

Fig. 4. Distribution of $\mathrm{PM}_{2.5}$ dust concentrations at successive distances from the manhole with the leachate 1 . 


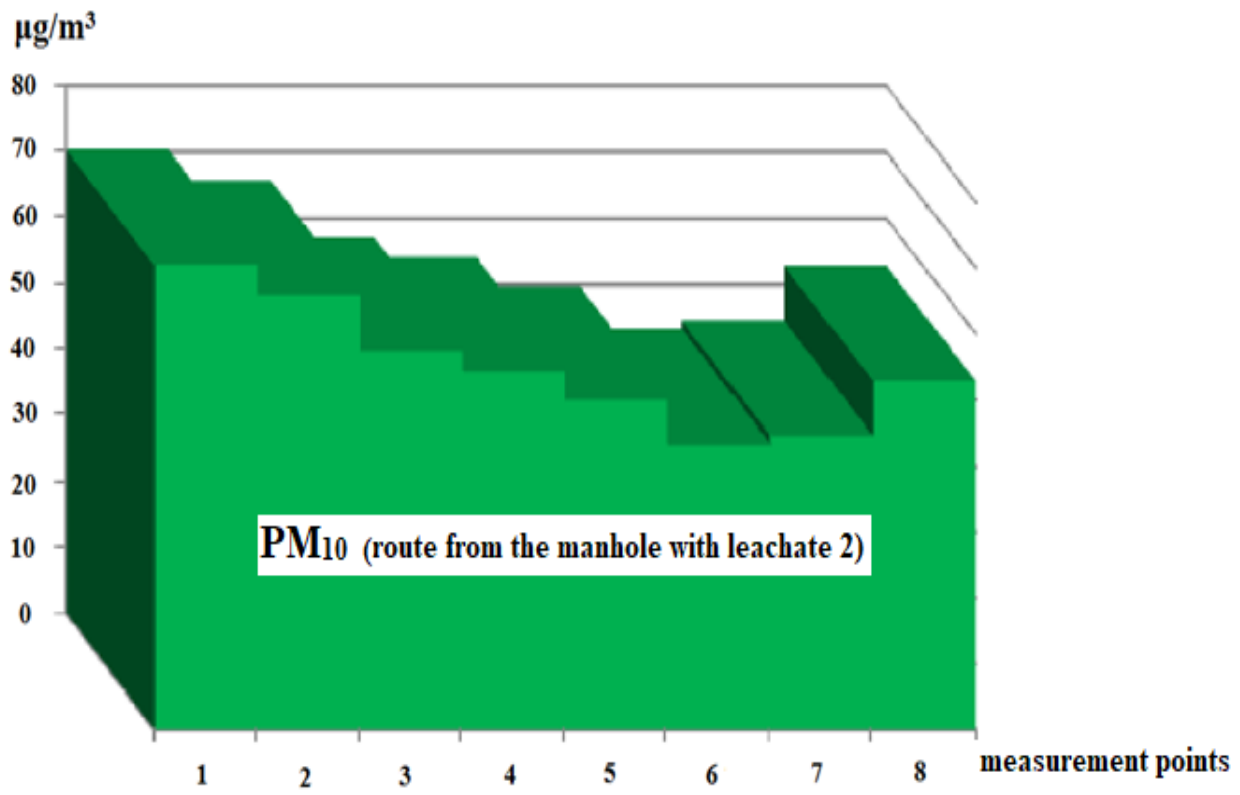

Fig. 5. Distribution of $\mathrm{PM}_{10}$ dust concentrations in the following distances from the manhole with the leachate 2.

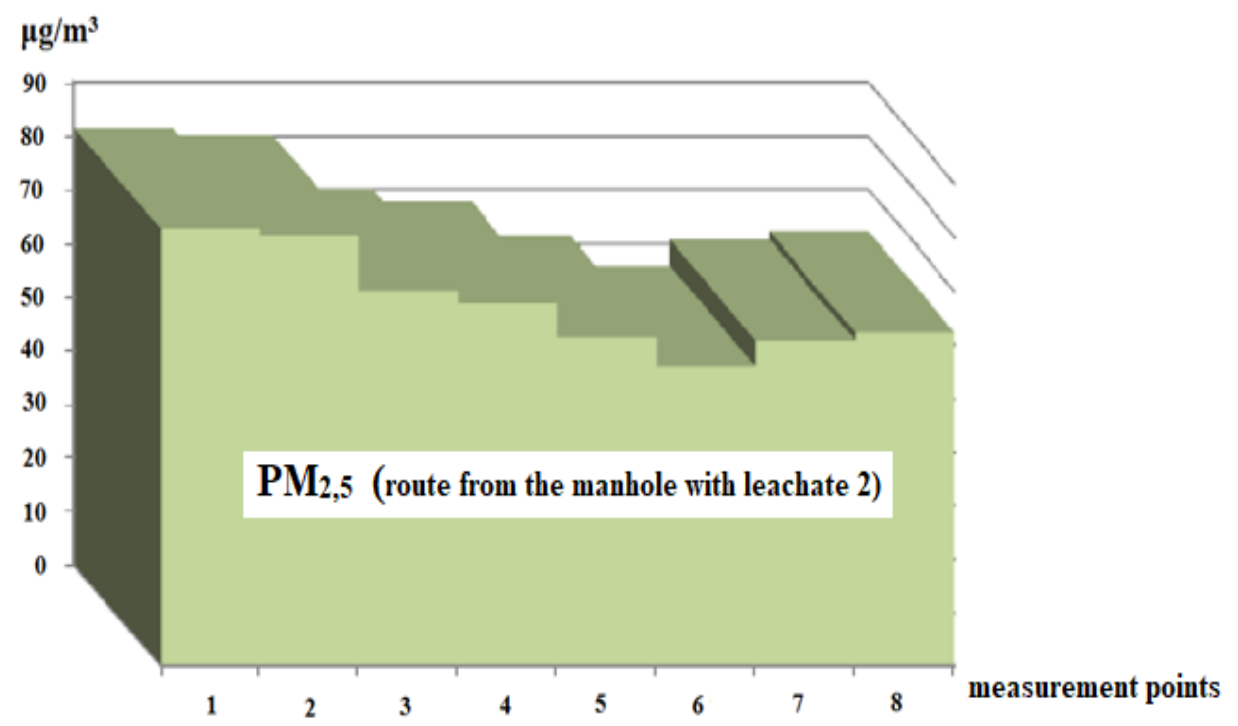

Fig. 6. Distribution of $\mathrm{PM}_{2,5}$ dust concentrations in the following distances from the manhole with the leachate 2 .

Figure 7 shows the total results of $\mathrm{PM}_{2.5}$ and $\mathrm{PM}_{10}$ dust concentrations for all points located at selected distances from both manholes. 


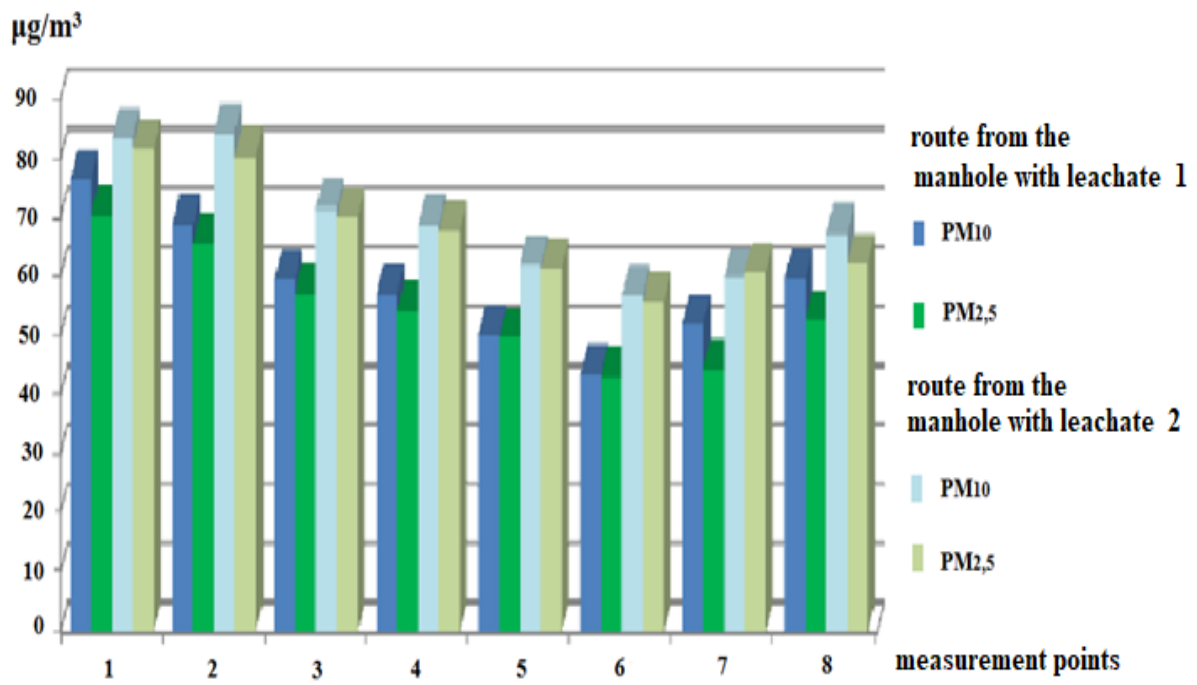

Fig. 7. Distribution of $\mathrm{PM}_{2,5}$ and $\mathrm{PM}_{10}$ dust concentrations at successive distances from both manholes.

Measurements of dust concentrations were made for orientation purposes to plan measurements in the following years. The tests were carried out under various atmospheric conditions. However, it can be concluded that the obtained results indicate that the permissible dust concentrations have been exceeded despite the fact that the landfill is already closed and that the top and side escarpments are being recovered. This may indicate that the reclamation layers covering the top and slopes of the landfill are not yet seated. At the same landfill, they are higher. This is also influenced by the internal road in the landfill, where the wells with leachate are located. It is also possible to consider the effect of dust deposited on the adjacent landfill sites while it was still in operation. The proximity of the access road to the landfill, which at the moment is not protected by separate covers, which can completely eliminate its impact on the marking, also has a significant impact on the measurement results. This is visible in the dust concentrations determined at points on the designated measurement routes from 1 and 2 wells, both nearly parallel to the road. The determined dust concentrations from the route from well 2 located further from the road are lower. The influence of a thoroughfare perpendicular to the access road to the storage site is also important. This is reflected by the heights of the determined concentrations dust at the points in the vicinity. In connection with potential hazards, it is necessary to monitor the concentration of suspended dust in order to increase the safety of the population.

\section{References}

1. D. Dmochowski, A. Dmochowska, S. Biedugnis, ROS 17 (2015)

2. T. Wesierski, M. Majder-Lopatka, W. Wasik, Przem. Chem. 96, 5 (2017)

3. M. Majder-Lopatka, W. Rogula-Kozlowska, W. Wasik, E3S Web of Conferences 44 (2018)

4. A. Piechota, A. Polanczyk, A. Goraca, Pharmacol. Rep. 62 (2010)

5. M. Majder-Lopatka and T. Wesierski, E3S Web of Conferences 46 (2018)

6. M. Majder-Lopatka, T. Wesierski, W. Wasik, BITP 42, 8 (2016)

7. Z. Salamonowicz, M. Kotowski, M. Polka, W. Barnat, Bull. Pol. Ac.: Tech. 63 (2015) 
8. W. Jarosz, Z. Salamonowicz, M. Majder-Lopatka, R. Matuszkiewicz, A. Dmochowska, Przem. Chem. 93 (2014)

9. Z. Salamonowicz, M. Kotowski, M. Polka, W. Barnat, Przem. Chem. 93 (2014)

10. A. Piechota-Polanczyk, A. Jozkowicz, Curr. Drug Targets 17 (2016)

11. A. Polanczyk, P. Wawrzyniak, I. Zbicinski, Drying Technol. 31, 10 (2013)

12. P. Wawrzyniak, A. Polanczyk, I. Zbicinski, M. Jaskulski, M. Podyma, J. Rabaeva, Drying Technol. 30, 10 (2012)

13. Z. Salamonowicz, R. Makowski, E3S Web of Conferences 44 (2018)

14. P. Wawrzyniak, M. Podyma, I. Zbicinski, Z. Bartczak, A. Polanczyk, J. Rabaeva, Drying Technol. 30, 9 (2012)

15. A. Piechota, A. Goraca, J. Physiol. Pharmacol. 62 (2011)

16. Z. Salamonowicz, M. Wolinski, M. Sobolewski, M. Polka, Przem. Chem. 93 (2014)

17. Z. Salamonowicz, M. Majder-Lopatka, Safe. Fire Techn. 30 (2013)

18. A. Polanczyk, Z. Salamonowicz, E3S Web of Conferences 44, 8 (2018)

19. A. Polanczyk, M. Podgorski, T. Wozniak, L. Stefanczyk, M. Strzelecki, Medicina 54, 15 (2018)

20. A. Polanczyk, M. Podgorski, M. Polanczyk, N. Veshkina, I. Zbicinski, L. Stefanczyk, C. Neumayer, Interact Cardiovasc Thorac Surg (2018)

21. A. Piechota-Polanczyk, M. Wlodarczyk, A. Sobolewska-Wlodarczyk, M. Jonakowski, A. Pilarczyk, K. Stec-Michalska, M. Wisniewska-Jarosinska, J. Fichna, Dig. Dis. Sci. 62 (2017)

22. A. Piechota-Polanczyk, M. Zielinska, D. Piekielny, J. Fichna, Biomed. Pharmacother. 84 (2016)

23. M. Polka, Z. Salamonowicz, M. Wolinski, B. Kukfisz, Procedia. Eng. 45 (2012)

24. Z. Salamonowicz, W. Jarosz, BITP 3 (2012)

25. M. Wlodarczyk, A. Sobolewska-Wlodarczyk, A.I. Cygankiewicz, D. Jacenik, A. Piechota-Polanczyk, K. Stec-Michalska, W.M. Krajewska, J. Fichna, M. WisniewskaJarosinska, J. Gastrointestin. Liver Dis. 26 (2017)

26. M. Salaga, L.V. Blomster, A. Piechota-Polanczyk, M. Zielinska, D. Jacenik, A.I. Cygankiewicz, W.M. Krajewska, J.D. Mikkelsen, J. Fichna, J. Pharmacol. Exp. Ther. 356 (2016)

27. A. Piechota-Polanczyk, S. Demyanets, O. Nykonenko, I. Huk, M. Mittlboeck, C.M. Domenig, C. Neumayer, J. Wojta, J. Nanobachvili, M. Klinger, Eur. J. Vasc. Endovasc. Surg. 45 (2013)

28. A. Polanczyk, M. Podyma, L. Stefanczyk, I. Zbicinski, Chem. Eng. Process 33, 9 (2012)

29. T. Wesierski, M. Majder-Lopatka, R. Matuszkiewicz, R. Porowski, Przem. Chem. 91, 3 (2012)

30. A. Piechota-Polanczyk, A. Goraca, Pharmacol. Rep. 64 (2012)

31. A. Piechota, A. Polanczyk, A. Goraca, Pharmacol. Rep. 63 (2011)

32. M. Baddock, C. Strong, J. Leys, S. Heidenreich, E.Tews, G. McTainsh, Atmos. Environ. 89 (2014)

33. E.Chalvatzaki, T. Glytsos, M. Lazaridis, Int. J. Environ. Health Res. 25, 5 (2015)

34. P. Dagsson-Waldhauserova, O. Arnalds, H. Olafsson, Icel. Agric. Sci. 27 (2014) 
35. A. Dmochowska. Statute SGSP (2015)

36. A. Polanczyk, M. Podyma, L. Stefanczyk, W. Szubert, I. Zbicinski, J. Biomech. 48 (2015)

37. W. Eilenberg, S. Stojkovic, A. Piechota-Polanczyk, C. Kaun, S. Rauscher, M. Groger, M. Klinger, J. Wojta, C. Neumayer, I. Huk, S. Demyanets, Eur. J. Vasc. Endovasc. Surg. 51 (2016)

38. H. Zatorski, M. Salaga, M. Zielinska, A. Piechota-Polanczyk, K. Owczarek, R. Kordek, U. Lewandowska, C. Chen, J. Fichna, Naunyn. Schmiedebergs. Arch. Pharmacol. 388 (2015)

39. A. Polanczyk, M. Strzelecki, T. Wozniak, W. Szubert, L. Stefanczyk, Found.Comp. Dec. Sci. 42, 13 (2017)

40. D. Dmochowski, A. Dmochowska, S. Biedugnis, ROS 17 (2015)

41. M. Tytla, A. Dmochowska, D. Dmochowski, E3S Web of Conferences 44 (2018)

42. M. Majder-Łopatka, T. Wesierski, W. Wąsik, BITP 42, 2 (2016)

43. A. Polanczy, T. Wozniak, M. Strzelecki, W. Szubert, L. Stefanczyk, Signal Process. SPA 5 (2016)

44. A. Zieminska-Stolarska, A. Polanczyk, I. Zbicinski, J. Hydrol. Hydromech. 644, 8 (2015)

45. L. Freire, M. Chamecki, J. Gillies, Meteorology 160, 2 (2016)

46. A. Polanczyk, A. Piechota-Polanczyk, L. Stefanczyk, PlosOne 12 (2017)

47. A. Polanczyk, M. Podyma, L. Trebinski, J. Chrzastek, I. Zbicinski, L. Stefanczyk, PLoS One 11 (2016)

48. A. Polanczyk, Z. Salamonowicz, E3S Web of Conferences 44 (2018)

49. Z. Yangyue, H. Ruifeng, Phys. Fluids 30 (2018)

50. A. Polanczyk, A. Piechota-Polanczyk, C. Domenig, J. Nanobachvili, I. Huk, C. Neumayer, Appl. Sci. 8, 14 (2018)

51. A. Polanczyk, M. Klinger, J. Nonobachvili, I. Huk, C. Neumayer, Appl. Sci. 8, 12 (2018)

52. M. Salaga, U. Lewandowska, D. Sosnowska, P.K. Zakrzewski, A.I. Cygankiewicz, A. Piechota-Polanczyk, M. Sobczak, P. Mosinska, C. Chen, W.M. Krajewska and J.

Fichna, Naunyn. Schmiedebergs Arch. Pharmacol. 387 (2014)

53. https://www.google.pl/search?q=pył+zawieszony (2018) 